\title{
Lugares inestables. Neoesclavismo en el siglo XXI en los campos freseros onubenses en España
}

\section{Unstable Places. Modern-Day Slavery of the 21st Century in the Strawberry Sector in Huelva in Spain}

Juan Carlos Romero Villadóniga ${ }^{1}$

\section{RESUMEN}

En un mundo globalizado, la necesidad de un futuro mejor hace que ingentes cantidades de seres humanos busquen refugio en las áreas más prósperas. La necesidad de alcanzar la tierra prometida provoca que vivan en una liminalidad entre lo legal y lo prohibido, siendo esto más visible en contextos donde se necesitan grandes cantidades de mano de obra temporal. Este es el caso de los espacios freseros de la provincia de Huelva, España, donde en temporada de recolección se produce una masificación y un hacinamiento en los asentamientos temporales, recogiendo el presente artículo las violencias sistémicas y simbólicas que se producen en estos contextos.

Palabras clave: 1. Migraciones, 2. liminalidad, 3. violencias, 4. resistencias, 5. Huelva, España.

\section{ABSTRACT}

In a globalized world, the pursuit of a better future means that large numbers of people seek refuge in the most prosperous areas. Their need to reach the promised land takes them to the frontier between the legal and the illegal, which is more visible in contexts where temporary labor is needed. That is particularly the case of the strawberry growing fields in the province of Huelva, Spain, where temporary settlements are overcrowded with immigrants during the harvesting season. This article describes the systemic and symbolic violence that takes place in these contexts.

Keywords: 1. Migration, 2. liminality, 3. violence, 4. resistance, 5. Huelva, Spain.

Fecha de recepción: 06 de marzo de 2018

Fecha de aceptación: 11 de julio de 2018

Publicación en web: 3 de abril de 2020

1 Universidad de Huelva, España, jucarovi66@gmail.com, https://orcid.org/0000-0002$\underline{0835-1636}$ 


\section{INTRODUCCIÓN}

\section{La complejidad de las relaciones humanas}

Aunque el fenómeno de la inmigración no es algo reciente, quizá en los últimos tiempos, a medida que la globalización se ha ido extendiendo por todo el planeta, la inmigración ha tomado una visibilización mucho más presente en la cotidianeidad de los sujetos. Así, la presente investigación trata de visibilizar las relaciones asimétricas de poder que se generan entre una comunidad receptora y una inmigrante. Para ello se tomará como objeto de estudio las relaciones, visiones, discursos y prácticas que se establecen entre inmigrantes temporeros de origen africano, básicamente ubicados en asentamientos ilegales repartidos por la geografía litoral onubense, y la población de origen en los asentamientos.

Esta investigación tiene un campo de estudio muy concreto y de marcada actualidad, y presta especial interés a fenómenos migratorios presentes en las poblaciones de Lepe, Lucena del Puerto, Moguer y Palos de la Frontera, o el "Dorado del 'oro rojo' onubense", en Huelva, España, donde una agricultura intensiva ligada con la producción de fresas y arándanos, altamente tecnificada, se ha convertido en uno de los principales motores económicos de la comunidad andaluza. Nos adentraremos en los asentamientos inestables donde conviven cerca de 8000 inmigrantes, muchos de ellos indocumentados, y con escasas posibilidades de regreso a sus lugares de origen, al haber entrado en una situación de no retorno.

Para este análisis vamos a utilizar el paradigma de la complejidad de Edgar Morin (2004) como vehiculizador del discurso, ya que partimos de la idea de la imposibilidad de poder reducir una problemática de este calibre a una mera suma de sus partes, lo que generaría una visión reduccionista y sesgada de la realidad. Del mismo modo, para poder delimitar el contexto etnográfico de los distintos lugares y espacios donde se desarrolla nuestro contexto de investigación, hemos optado por el enfoque multisituado formulado por Marcus (2001).

\section{Comenzando la travesía}

El nuevo desorden global es ante todo asimétrico, basándose en relaciones de $\operatorname{poder}^{2}$ que reproducen y legitiman situaciones de opresión entre sujetos. El lenguaje genera estructuras y, para el caso que nos ocupa, nunca mejor dicho. El inmigrante, muy diferente del residente extranjero, ${ }^{3}$ se convierte en el eslabón inferior de esta cadena de poder; se convierte en el

${ }^{2}$ Entendiendo, al igual de Foucault (2000), que el poder no se posee, sino que es una estrategia de control compuesta por una red de relaciones estratégicas complejas. Ello permitirá producir sujetos, discursos y verdades las cuales penetrarán y darán sentido desde todos los nexos sociales, mutando gracias a su capacidad de adaptación.

${ }^{3}$ Para Manuel Delgado (2011) debe establecerse una diferenciación entre los conceptos "inmigrante" y "residente extranjero", ya que van a ser dos atributos aplicados desde la 
vulnerable de los vulnerables, en el estigmatizado de los estigmatizados. Y es que como apunta Zizek (2016):

Lo que Sloterdijk señaló correctamente es que la globalización capitalista no representa tan sólo apertura y conquista, sino también un mundo encerrado en sí mismo que separa el Interior de su Exterior. Los dos aspectos son inseparables: el alcance global del capitalismo se fundamenta en la manera en que introduce una división radical de clases en todo el mundo, separando a los que están protegidos por la esfera de los que quedan fuera de su cobertura (Zizek, 2016, p.12)

Existe una asociación directa entre los conceptos inmigrante-globalización-economía. El nuevo orden global definido por la desregulación, la flexibilidad y la competitividad (Haro, 2014), genera situaciones de profunda inestabilidad no solo en los mercados, sino también en los sujetos.

Los grandes movimientos de población responden a las lógicas hegemónicas del mercado y a sus necesidades. Autores como Morin (1993), Appadurai (2007) o Pogge (2000), han puesto el dedo en la llaga en cuanto a la importancia que juegan las grandes transnacionales en la actual configuración planetaria, así como en la necesidad de un cambio global. En este sentido, Zizek (2016) expone:

Una buena manera de comenzar... es centrarse en lo que no podemos denominar sino economía política de los refugiados, para desarrollar la conciencia clara de qué y quién está causando dichos movimientos de masas. Lo primero que hemos de hacer es localizar la causa última en la dinámica del capitalismo global y también en el proceso de intervenciones militares... El actual desorden es la auténtica faz del Nuevo Orden Mundial. Abandonados a su suerte, los africanos no conseguirán cambiar sus sociedades. ¿Por qué no?, Porque nosotros, los europeos, se lo impedimos (Zizek, 2016, p.51)

En la actual dinámica planetaria el sujeto se encuentra en una situación de fragilidad extrema. Esta marcada vulnerabilidad de colectivos estigmatizados por categorías tan dispares como la etnicidad, la orientación sexual o la condición de clase, genera la creación

sociedad receptora tendente al mantenimiento de relaciones asimétricas de poder. Así, el atributo inmigrante estaría asociado desde la comunidad receptora, a un estigma y principio negativo, ligándose a características tales como intruso, pobre, inferior en el sistema de estratificación social, o peligroso para la seguridad de la comunidad. Por el contrario, el residente extranjero se correspondería con ciudadanos provenientes de espacios con un nivel de desarrollo económico superior, los cuales gozan de una situación legal menos integrada, pero que no van a sufrir ni explotación, ni mucho menos, rechazo, al considerarse como "invitados". La diferencia entre ambos no hace sino hacernos ver cómo el proceso de construcción de la alteridad no está sino mediatizado por una gran cantidad de intersecciones tales como el origen social o su étnica, pero quizás con igual fuerza, su clase social, sus niveles formativos, o su acceso a las cuotas de poder. 
de fronteras perfectamente delimitadas, segregaciones físicas y simbólicas, al objeto de enfocar la alteridad desde posicionamientos de mixofobia, en un claro intento de invisibilización de las contradicciones del actual sistema neoliberal.

De esta forma, el inmigrante es constreñido intencionalmente de su capacidad de agencia y de su carácter político para entrar en los círculos de la dependencia, en un claro intento de invisibilización de las contradicciones de un sistema que los ha generado y los necesita como mano de obra barata y disponible para la reproducción del sistema, generando violencias simbólicas, al tiempo que sistemáticas, en las corporeidades.

La población temporera inmigrante va a ser doblemente estigmatizada a partir de un estereotipo que cosificará y esencializará su condición social como "un mal inevitable" de la sociedad en la que se inserta sus prácticas cotidianas, "no son vistos como ciudadanos con derecho a tener derechos, sino como seres humanos carentes que deben ser atendidos por la caridad pública o privada" (Dagnino, Olvera y Panfichi, 2006, p. 63)

A lo anterior se le sumará la lejanía de referentes identitarios, ya que la salida de los lugares donde se ha producido la memorialización de sus vivencias (Biasatti y Compañy, 2014), implica al mismo tiempo diluir "los soportes de la existencia social, esto es, un conjunto de cosas y personas ordinarias que son portadoras de significados: tierra, casa, aldea, ciudad, padres, posesiones, trabajos y otras referencias cotidianas" (Bauman 2005, p. 102)

Con escasas perspectivas de asimilación a los cuerpos sociales receptores, la vida del inmigrante se cifra en la transitoriedad, la indefinición y la provisionalidad, no permitiendo generar lazos afectivos con el entorno, convirtiéndose en una tercera marca del estigma, el estado de soledad, siendo esta más marcada cuando las diferencias culturales entre el inmigrante y la sociedad receptora se acentúan, generando sentimientos de rabia e indignación, como apunta Zizek (2016) o Appadurai (2007).

Así pues ser inmigrante implica asumir el estigma de un rol en una cultura externa a la suya, con imaginarios y socialidades igualmente diferentes; implica ir a un entorno hostil, donde las redes sociales son débiles en número y siempre será visto como el otro, siempre en la liminalidad entre la aceptación con reservas o la exclusión por parte de la sociedad receptora. Ello traerá cambios en sus auto-ego-finalidades, modificando igualmente su autoego-centrismo (Solana, 2000), influyendo por tanto, en su reflexividad como sujeto que actúa desde la intersubjetividad (Pozzoli, 2006).

\section{EL MAPA DE LA VERGÜENZA. EL PROBLEMA DE LOS ASENTAMIENTOS INESTABLES DE TEMPOREROS}


No hay nada más invisible que un inmigrante, y más cuando carece de documentación en regla. Este es el caso que nos ocupa, ya que los asentamientos de temporeros, especialmente habitados por población africana, en la provincia de Huelva, España, no son sino fronteras entre la existencia como sujetos ante la falta de reconocimiento legal por parte de las autoridades.

El fenómeno de las migraciones levanta pasiones encontradas. Haciendo un balance global de las inmigraciones en el territorio nacional, podemos encontrar que no todas las regiones emisoras han aportado el mismo número de las mismas a lo largo del tiempo. De esta forma, comparando los datos ofrecidos por el INE referidos al año 2018, podemos observar cómo del total de colectividades que conforman el mosaico étnico de los trabajadores temporeros en España, el que mayor peso detenta van a ser los colectivos marroquí (769 050) y rumano (673 017), con cifras que se aproximan al millón de personas, teniendo un menor peso cuantitativo las masas provenientes de otras áreas, especialmente las del centro y sur de continente africano, quienes aportan unos 150000 inmigrantes. Este dato resulta de gran importancia ya que, como veremos más adelante, a nivel nacional esta proporción no va a tener correspondencia con el caso onubense y mucho menos con el colectivo que se asienta en los campamentos temporales.

Esta misma tendencia continúa, como puede ejemplificarse en el caso de la provincia de Huelva. De esta forma, para el mismo año 2018 el INE ${ }^{4}$ arroja que de un total de 41923 extranjeros residentes en la provincia de Huelva, Rumanía va a ser la que aporte el mayor número al global (14 943), pasando la población marroquí a ocupar un segundo puesto con 10 037, destacando igualmente los casos de Senegal (761) y Nigeria (138). Sin embargo, estos datos debemos tomarlos con cautela ya que, recordemos, estamos hablando de población legalmente instalada en territorio peninsular, no viniendo censada la población indocumentada y en situación de ilegalidad.

Sin embargo, a pesar de este último dato, cuando logramos bajar a una escala local, y más concretamente, a las cuatro poblaciones objeto de estudio con mayor aporte de población inmigrante, nos encontramos que nuevamente se produce una práctica hegemónica de la población magrebí frente al resto de las nacionales presentes en la zona, siendo la población rumana prácticamente residual, al asentarse en otras poblaciones de la zona o bien, en la capital. Llama la atención cómo los datos ofrecidos por el INE (tabla 1) prácticamente no arrojan población africana ni magrebí en la zona, lo que refuerza la idea, como veremos más adelante, de que la población de origen subsahariano se encuentra en situación de invisibilidad para las estadísticas oficiales.

4 Todos los datos han sido extraídos de las bases oficiales del Instituto Nacional de Estadística, en la dirección http://www.ine.es/jaxi/Tabla.htm?path=/t20/e245/p04/provi/10/\&file=0ccaa002.px 
Tabla 1. Principales nacionalidades recogidas por el INE en las cuatro poblaciones freseras

\begin{tabular}{lccccc}
\hline \multicolumn{5}{c}{ Principales nacionalidades objeto de estudio } \\
\hline $\begin{array}{l}\text { Principales } \\
\text { nacionalidades }\end{array}$ & Total & Rumanía & Argelia & Marruecos & $\begin{array}{c}\text { Otros países } \\
\text { de África }\end{array}$ \\
Total & 12677 & 4711 & 230 & 3510 & 1925 \\
Lepe & 4273 & 1371 & 122 & 879 & 776 \\
Lucena del Puerto & 1086 & 579 & 26 & 315 & 45 \\
Moguer & 5533 & 1888 & 75 & 1965 & 920 \\
Palos de la Frontera & 1785 & 873 & 7 & 351 & 184 \\
\hline
\end{tabular}

Fuente: Padrones municipales de habitantes del Instituto Nacional de Estadística, Municipio de Palos de la Frontera (INE, 2017).

Si se observa por municipios, el baile de las cifras cobra un protagonismo muy especial, ya que estas cifras chocan cuando entramos en niveles de desagregación más concretos, como puede ser el nivel inframunicipal. De esta forma, las variaciones encontrables pueden resultar en principio contradictorias, aunque no lo son ni mucho menos. Así, tomando como referencia el caso del municipio de Palos de la Frontera, encontramos que en la actualidad se encuentran registrados 1785 inmigrantes en esta población, siendo la mayor parte procedente de Europa del Este y de género femenino, que suele ocupar el territorio en determinadas épocas del año para la siembra y recogida de fresas y otros productos rojos. Este dato contrasta con la población objeto de la presente investigación, de origen subsahariano principalmente, de ahí el baile de cifras, pues en las anteriores referencias destacará la importancia de la población africana principalmente en el campo onubense

Un aspecto realmente interesante de este nivel de desagregación es que permite conocer el modelo de ocupación del territorio. Como es de suponer, nuevamente tomando como referencia el caso de Palos de la Frontera, la forma de ocupar y habitar el espacio nos informa acerca de las asimetrías entre inmigrantes y locales. Así, uno de cada tres inmigrantes vive en ámbitos rurales próximos a las explotaciones agrícolas, frente a uno de cada siete lugareños, lo cual nos habla de cómo es en el ámbito rural donde desarrolla la cotidianeidad la población inmigrante residente en la zona fresera onubense, por lo que podemos hablar de una jerarquía del espacio la cual se traduce en una apropiación simbólica de esta que establece diferencias entre los lugareños y el colectivo inmigrante.

Tabla 2. Asentamiento según origen en Palos de la Frontera y término municipal 2017 2013 2009 


\begin{tabular}{|c|c|c|c|c|c|c|c|c|c|}
\hline & Total & Española & Extranjera & Total & Esp. & EXT. & Total & Esp. & EXT. \\
\hline $\begin{array}{l}\text { Tipo de zona } \\
\text { (detalle) }\end{array}$ & \multicolumn{9}{|c|}{ Cantidad de personas } \\
\hline Total & 10885 & 9100 & 1785 & 10196 & 8389 & 1807 & 9043 & 7792 & 1251 \\
\hline $\begin{array}{l}\text { Zona rural } \\
(2000 \\
\text { habitantes o } \\
\text { menos) }\end{array}$ & 1905 & 1381 & 624 & 1807 & 1259 & 548 & 1393 & 1046 & 347 \\
\hline $\begin{array}{l}\text { Zona } \\
\text { intermedia } \\
\text { (2 001-10 } 000 \\
\text { habitantes) }\end{array}$ & 8509 & 7779 & 1161 & 8389 & 7130 & 1259 & 7650 & 6746 & 904 \\
\hline
\end{tabular}

Fuente: Padrones municipales de habitantes del Instituto Nacional de Estadística, Municipio de Palos de la Frontera (INE, 2017).

Estos datos obtenidos directamente del INE referidos al año 2016 (INE, 2017), resultan altamente cuestionables, ya que no recogen la población itinerante ni tampoco a la población inmigrante que carece de documentación legal para residir en el territorio español.

$\mathrm{Y}$ es que hablar de asentamientos de temporeros en Huelva es hablar de invisibilidad. No figuran en ninguna estadística oficial, no cuenta para los padrones, ni tampoco hay datos de estos en los registros de la Seguridad Social. Se trata de un colectivo estigmatizado invisibilizado para la administración, pero que tiene una amplia presencia en las zonas freseras más importantes a nivel provincial. De esta forma, el último recuento ofrecido por el sindicato obrero Comisiones Obreras (CCOO, 2016) no hace sino hacernos ver cómo en los diferentes asentamientos analizados, la composición multiétnica que da vida a esos lugares es muy diferente de las tendencias ofrecidas por las autoridades de manera oficial. Por esta razón, para la presente investigación debemos tomar como referencias la que, sin duda, es la estadística más concienzudamente elaborada hasta la fecha, a pesar de no tratarse de un organismo oficial.

La mayor parte de los asentamientos ilegales se encuentran ubicados entre las localidades de Lucena del Puerto-Bonares, Palos de la Frontera, Moguer y Lepe, aunque también es frecuente encontrar pequeños asentamientos dispersos por la costa onubenses. De todos, los asentamientos de Moguer van a ser los más numerosos y prolijos de identidades, teniendo en todos ellos un claro predominio de la población del África subsahariana frente a otros colectivos.

Tabla 3. Desglose de población inmigrante ubicada en los principales asentamientos de las poblaciones objeto de estudio a partir del recuento realizado por el sindicato 


\begin{tabular}{|c|c|c|c|c|}
\hline $\begin{array}{l}\text { Porcentaje } \\
\text { sobre el total }\end{array}$ & $\begin{array}{c}\text { Palos de la } \\
\text { Frontera } \\
36 \text { Mujeres/ } \\
1155 \text { Hombres }\end{array}$ & $\begin{array}{c}\text { Moguer } \\
100 \text { Mujeres/ } \\
3091 \text { Hombres }\end{array}$ & $\begin{array}{c}\text { Lepe } \\
\text { 4 Mujeres/ } \\
1400 \text { Hombres }\end{array}$ & $\begin{array}{c}\text { Lucena del } \\
\text { Puerto } \\
\text { 237 Mujeres/ } \\
1109 \text { Hombres }\end{array}$ \\
\hline Senegal & 33 & 4.6 & 17.2 & \\
\hline Mali & 15 & 37.8 & 52.8 & 6.7 \\
\hline Marruecos & 13 & 43.9 & 11.7 & 26.2 \\
\hline Gambia & 12 & 4.45 & & \\
\hline Guinea & 6 & 0.35 & 5.8 & \\
\hline Mauritania & 5 & 0.7 & & \\
\hline $\begin{array}{l}\text { Otros (Nigeria, } \\
\text { Ghana, } \\
\text { Burkina...) }\end{array}$ & 16 & $\begin{array}{l}\text { Costa de Marfil: } \\
0.93 \text {; Gambia: } \\
\text { 1.51; Libia: } \\
0.57 \text {; Otras: } \\
5.92\end{array}$ & $\begin{array}{l}\text { Costa de Marfil: } \\
\text { 0.99; Rumanía } \\
0.2 \text {; Otras: } \\
11.31\end{array}$ & $\begin{array}{l}\text { Rumanía: } 24 ; \\
\text { Ghana: } 32.4 ; \\
\text { Burkina: } 1.42 ; \\
\text { Nigeria: } 0.57 ; \\
\text { Otras: } 8.57 .\end{array}$ \\
\hline
\end{tabular}

Fuente: Comisiones Obreras (2016).

Como se puede comprobar en la tabla 3, los colectivos más numerosos provendrán de Mali y Senegal, encontrándose a cierta distancia, gitanos rumanos, y otras nacionalidades aunque en mucha menor proporción. Resulta poco menos que curioso observar cómo la agrupación no va a ser casual, habiendo nacionalidades minoritarias que se van a concentrar dentro de una misma área geográfica, muchas veces en un mismo campamento, lo cual nos hace ver cómo la nacionalidad puede ser un factor importante a la hora de explicar la distribución étnica de sus ocupantes. Un aspecto destacable del informe de CCOO sobre la situación de los asentamientos va a ser la profunda masculinización de sus ocupantes.

\section{ORO ROJO, ESCLAVOS INVISIBLES}

\section{Mucho te quiero amiguito, pero de pan poquito}

La solidaridad es un concepto entendido para la alteridad, nunca para uno mismo. Hay que tener mucho cuidado a la hora de abordar sus diferentes dimensiones, especialmente en contextos donde situaciones de multiculturalismo se unen a una marcada vulneración y exclusión social. Por esta razón, en los asentamientos ilegales ubicados por toda la geografía litoral onubense nos podemos encontrar cómo van a producirse situaciones en las cuáles los discursos y las prácticas no siempre se van a ver correspondidas.

El presente estudio ha establecido una metodología basada en la observación, en sus formas pasivas y participante; también se realizaron 10 entrevistas semiestructuradas: dos a 
miembros de colectivos que trabajan con población inmigrante, una a un miembro de los servicios de atención al inmigrante de los cuerpos de seguridad, cuatro a integrantes de varios asentamientos de la zona, así como a tres lugareños. El objetivo consistirá en evidenciar las contradicciones existentes entre los discursos y las prácticas de todos los actores, recurriendo a un ejercicio constante de extrañamiento de las escenas y los contextos, ya que la proximidad geográfica, así como la cotidianeidad, en este caso del investigador con los sujetos de estudio, obligaba a ello.

Para poder preservar el anonimato de los informantes no se utilizan nombres reales en las citas de las entrevistas, muchas de ellas realizadas con gran cantidad limitaciones al no consentir su grabado, debiéndose recurrir a la transcripción instantánea de las mismas.

Cuando, en cierta ocasión leí a Juan Peris (2006), trabajador social de Cáritas encargado del trabajo con inmigrantes en la costa onubense, sus palabras me causaron un gran impacto, ya que resumía gráficamente la realidad visual y emocional de este colectivo:

En los bosques cercanos y en la periferia de los municipios agrícolas se forman asentamientos de chabolas levantadas por los inmigrantes -documentados e indocumentados- con los plásticos de las fresas, constituyendo un ejército de mano de obra de reserva que espera su oportunidad, bien con los contratos que no son cubiertos con los realizados en origen, o bien trabajando días concretosfestivos, refuerzos en plena campaña-(Peris, 2006, p. 172).

De esta forma tan aséptica pero real, Peris relata las condiciones de vida cotidiana de los inmigrantes en asentamientos próximos a las grandes explotaciones freseras, que tanto rendimiento económico aportan a sus propietarios. Llegados desde diferentes rincones de África o de las zonas más deprimidas de Europa del Este, como Rumanía (gitanos especialmente), acuden al sueño europeo engañados en la vana idea de alcanzar un futuro mejor. Muchos de ellos cuentan con formación académica o trabajos medianamente estables, abandonan sus lugares de nacimiento en un intento de poder dar un futuro a su familia o su entorno más próximo, como es el caso de Lumumba, natural de Senegal, quien a sus 29 años muestra en su mirada el rigor de la vida:

Yo nací en Darou, en Senegal, y soy el hermano mayor de nueve. Me casé y tengo cuatro hijos. Como allí no hay para vivir me dijeron de poder venir a España, que aquí yo encontraría trabajo seguro y ganaría para poder enviar dinero a casa y montar un negocio en el futuro. Con los ahorros que tenía y lo que me prestaron mis familiares, con la promesa de devolverlo, estuve casi dos años por diferentes lugares hasta que pude pasar a España. Uno de mis peores momentos fue en el monte Gurugú cuando la policía marroquí venía y nos golpeaba con palos. Pero al final pude pasar a España y aquí estoy, aunque no se bien por qué (Lumumba, comunicación personal, 5 de marzo de 2016).

No puedo entretenerme mucho con la narración de Lumumba, ya que desconfía de las intenciones de la charla, y no quiere ser grabado. La desconfianza es común entre estos ciudadanos invisibles residentes de arquitecturas efímeras, ya que no suelen acercarse por 
allí los lugareños, salvo contadas excepciones; procuran en todo momento mantener las distancias, no sabemos muy bien si por miedo o por desconfianza. Ello tiene su lógica si entendemos, siguiendo el paradigma de la complejidad de Morin (2004), que en el ser humano hay dos principios relacionales respecto a la otredad, el sociocentrismo y la socioexclusión, en los que se acepta a la otredad por su cercanía o bien, se la aleja (Solana, 2000).

Y es que la dimensión de la integración reviste múltiples aristas, dependiendo del sujeto que así la ponga en marcha. Como el propio Llobera (1990) o Manuel Delgado (2006) comentan, hay que tener mucho cuidado a la hora de abordar los conceptos de integración y tolerancia, ya que aparte de ser conceptos ligados a una dimensión cultural concreta suelen ser multidireccionales, pudiendo encontrarnos con situaciones de intolerancia, incluso desde los propios colectivos inmigrantes, o hasta en las asociaciones que precisamente están luchando contra ese fenómeno. De esta forma, no resulta infrecuente encontrar en los medios de comunicación locales enfrentamientos entre colectivos de inmigrantes rumanos con africanos, no siendo sino una tónica común entre estos. Ello se manifiesta en la existencia de toda una ocupación y liturgia simbólica del espacio en estos campamentos, donde se marcan los roles, los tiempos y los rituales.

Así, un paseo por los asentamientos intemporales nos permite ver cómo no se producen mezclas entre diferentes áreas culturales, teniendo los campamentos de sujetos provenientes de Europa del Este una ubicación completamente segregada del resto de asentamientos, especialmente los compuestos por africanos, lo cual nos hace ver cómo el fenómeno de la integración no es tan fácil ni es tampoco exclusivo y obligatorio sólo de las comunidades receptoras (Delgado 2006). En este sentido, Miha, gitano de origen rumano asentado en un campamento de Lucena del Puerto, lo dice de forma muy clara a lo largo de una de las charlas realizadas con él: ${ }^{5}$

Nosotros [por los gitanos rumanos de su asentamiento] no queremos cuenta con los negros. Ellos están allí y nosotros aquí. Para mí, mi gente es fundamental, no deseo estar con los de otros lugares, ya que tampoco lo necesito. Cuando algún compatriota se ha ido a vivir a algún campamento de los negros al final ha tenido que salir huyendo o ha terminado mal, a palos. Les robaban las cosas, lo dejaban de lado porque no hablaban sus idiomas o entraban en su casa y sin mediar palabra tomaban lo que deseaban. En el campo pasa igual, estamos trabajando y no hay problemas, pero cuando se juntan muchos hay siempre problemas seguro (Miha, comunicación personal, 9 de abril de 2016).

Con su español entrecortado, Miha nos informa de cómo no es oro todo lo que reluce en estos contextos, así de cómo la superviviencia muchas veces obliga a situaciones de conflicto

${ }^{5}$ El caso de Miha es especial a la hora de la recogida de información, ya que el conocerlo desde hace ya algunos años ha facilitado mucho la labor, al haberse realizado en contextos informales. 
entre los sujetos que viven en estos asentamientos. La intolerancia y la mixofobia se hace latente no solo en la comunidad receptora, sino igualmente entre los inmigrantes. Imaginarios divergentes, redes sociales limitadas a sus compatriotas, sensación de exclusión social no son sino resortes que hacen que se articule en el sujeto una situación de tensión y de miedo, de recelo hacia la otredad. Y es que la convivencia con el miedo es quizás uno de los principales elementos de cohesión de la grupalidad frente a la alteridad (Bauman 2005).

Este miedo es aún más evidente cuando en estos asentamientos surge la palabra retorno, despertando sentimientos encontrados entre ellos. Lumunba lo tiene claro en este sentido:

Si pudiera me volvería a mi tierra con los ojos cerrados, pero ahora estoy en tierra de nadie. Aquí en España no tengo papeles, no puedo trabajar casi nunca, solo cuando quieren en el campo y no gano suficiente para enviar para casa. Pero tampoco tengo dinero para volver ni para pagar lo que me han prestado allí. En mi país tenía un trabajo y comida todos los días, pero aquí no soy nadie y aunque quisiera volver no sé cómo lo haría (Lumumba, comunicación personal, 5 de marzo de 2016).

Aunque este no sea el caso de Miha, ya que tiene a muchos familiares repartidos por asentamientos de la provincia, también dedicados a labores agrícolas, sí que existe en sus palabras una añoranza por volver a sus orígenes, aunque la posición de partida de ambos es diametralmente diferente, ya que Miha dispone de documentación y es libre de poder moverse por cualquier parte de la geografía europea.

Y es que la situación de documentado-indocumentado marca la liminalidad entre el sujeto con derechos y el sin derechos, así como marca barreras invisibles entre el sujeto y la alteridad, las cuáles muchas veces nacen de los propios inmigrantes, ya que en su construcción intervienen elementos simbólicos provenientes de ambos lados. Ello se evidencia en aspectos como la misma entrada al campo de investigación, así como en el acceso a los informantes, encontrándonos con barreras tanto visibles como invisibles entre los informantes y uno mismo, lo cual nos recuerda a Llobera (1990) cuando reconoce cómo el propio antropólogo contiene sesgos racistas per se, al estar inmerso en un contexto cultural y social muy concreto. ${ }^{6}$ Como apunta Solana:

Las políticas de orientación universalista tienden a no tomar en cuenta las dimensiones identitarias, étnicas o culturales; consideran que las manifestaciones racistas afectan a individuos definidos como seres humanos con derechos y no a grupos definidos por su diferencia cultural (Solana, 2002, p. 143).

\footnotetext{
${ }^{6}$ Reconocemos que, quizás debido a la cercanía geográfica, cultural o quien sabe su etnia, las charlas mantenidas con Miha han resultado mucho más cómodas que las realizada con Lumumba, lo cual no hace sino hacernos reflexionar sobre hasta qué punto el sesgo racista humano puede influir a la hora de la apreciación de la alteridad.
} 
Afecta esta forma de violencia simbólica, en sus múltiples dimensiones y direcciones, también, a la cultura receptora de los inmigrantes, entre los que se demoniza su condición de vida, así como se estigmatiza su condición conflictiva. De esta forma no resulta difícil encontrar por parte de la ciudadanía expresiones como "no traen nada bueno", "sólo vienen aquí a robar y a vivir de la caridad", " no pueden vivir en su país, pero no dejan vivir tampoco en el nuestro". Los inmigrantes serán estigmatizados, asociándolos con inseguridad, con falta de tranquilidad, en un claro ritual de lo que Girard (2005), denominaría la "creación del chivo expiatorio", sobre el cual recaen todas las culpas en un intento de normalización de las condiciones de asimetría y poder entre clases sociales, legitimando la desigualdad. De esta forma, a lo largo de una charla mantenida con José, empresario fresero de la zona, queda más que patente esta visión estigmatizada del Otro:

Yo hago contratos de origen. Por medio de los organismos de aquí contrato a polacas y rumanas y vienen a mis campos a trabajar. Les doy empleo, casa y sueldo, y cuando acaba la temporada pues se vuelven nuevamente y aquí todos tan felices. La cosa cambia con los de las chabolas [por los asentamientos]. Todos los días vienen buscando trabajo y yo les digo que sin papeles no hay nada (José, comunicación personal, 15 de abril de 2016).

A lo largo de la conversación se me viene a la cabeza la charla con Lumumba, y de cómo en muchas ocasiones suele encontrar algún trabajo disperso en alguno que otro campo, especialmente en fines de semana, que es cuando las fuerzas de seguridad no dan batidas de control de trabajadores. Le pregunto a José si él contrata a indocumentados, o a inmigrantes provenientes de los asentamientos cercanos

Claro que se recurre a ellos, algún día especial cuando la temporada es más fuerte y no se encuentra a nadie, pero es algo excepcional y sólo por unos días. Además, da mucha pena verles vagabundear por esos campos y a veces hay que darles un poco de margen, tienen que comer por lo menos (José, comunicación personal, 15 de abril de 2016)

Bajo esta frase se esconderá toda una espada de Damocles, sacando a la luz una de las principales contradicciones existentes entre los discursos y las prácticas de los empresarios de la zona, ya que al mismo tiempo que critican el empleo de mano de obra indocumentada, contratan muy por debajo del precio de un trabajador legal a este colectivo, agravando aún más las asimetrías y la violencia estructural sobre ellos, al generar un neoesclavismo en toda regla. Se convierten así, los inmigrantes en situación irregular, en sujetos invisibles para la administración, mano de obra sobradamente cualificada para lo que reclama el mercado, esclavos a los pulsos del mercado y las necesidades de los empresarios agrícolas (Miedes y Redondo, 2007).

Esta invisibilización es comúnmente aceptada por todos los actores que participan en esta macabra obra de teatro, justificándose desde múltiples puntos de vista, unas veces desde el puramente humanitario, otras como justificación a las necesidades de mercado (Rodríguez 
y Breva, 2012). La connivencia de esta nueva forma de explotación con las estructuras del Estado es más que evidente, siendo prácticamente imposible poder sacar a la luz estas situaciones salvo por medio de organizaciones sindicales o asistenciales. En este sentido, ayuntamientos, fuerzas de seguridad y otros organismos viven en la liminalidad fronteriza entre lo que marca la ley y lo que el mercado demanda, jugando en múltiples ocasiones en la dialógica innata del ser humano. Tal es el caso de Damián, de los cuerpos y fuerzas de seguridad del Estado, quien realiza periódicamente batidas y controles por las explotaciones agrícolas onubenses, manifiestándose desde el anonimato con una clarividencia absoluta:

Claro que sabemos que hay inmigrantes ilegales en los campos, pero hay que intentar encontrar un equilibrio... A veces sabemos qué lugares debemos visitar y cuando vamos nos encontramos con todo en regla, pero sabemos que cuando nos demos la vuelta volverán los ilegales que están escondidos entre los pinares y todo volverá a la misma situación. Realmente es un problema que no podemos controlar (Damián, comunicación personal, 27 de abril de 2016).

A lo largo de la charla Damián me comenta cómo cuando tienen que acudir a algún asentamiento tienen miedo de encontrarse con situaciones para las que no están preparados para controlar, debiendo acudir varias unidades para un mejor control de las tensiones. Las peleas frecuentemente se producen, según él, por pequeños robos de pertenencias o de algún dinero que alguien tenía guardado para enviar a su familia, habiendo grupos de inmigrantes organizados según su nacionalidad, lo cual nos vuelve a la idea de cómo la cultura genera pequeñas islas exclusivas y excluyentes entre los ocupantes de estos asentamientos, los cuales territorializan el espacio vivido-espacio sentido a partir de su proximidad cultural, en una clara estrategia de supervivencia frente a la alteridad.

\section{El problema de acceso a la vivienda}

Uno de los factores determinantes a la hora de entender el fenómeno del chabolismo inmigrante en Huelva habría que buscarlo en el acceso a la vivienda por parte de estos. Para el Foro Para la Integración Social de los Inmigrantes, en sus estudios sectoriales (Rodríguez y Breva, 2012), hay varios factores que explican esta dificultad de acceso:

a) Por un lado, la población inmigrante buscaría recrear los vínculos, redes sociales y de solidaridad comunitarias que favorezcan su integración y adaptación al nuevo medio.

b) Por otro lado, existen evidentes dificultades para el acceso a la vivienda debido a la existencia de conductas discriminatorias y/o afán de lucro, por parte de determinados propietarios e intermediarios del mercado inmobiliario, que dificultan el acceso al alquiler (Foro para la Integración Social de los Inmigrantes, 2007). 
En todas las entrevistas realizadas, así como en las observaciones in situ, el problema de acceso a la vivienda es más que frecuente. Unas veces motivado por el deseo de pertenencia y de seguridad frente a su colectivo de iguales, otras veces por la actitud xenófoba de los lugareños, lo cierto es que se trata de un fenómeno de difícil solución (Olea, 2012). Dembele, de origen maliense -colectivo muy importante en los asentamientos de la localidad-, cuenta cómo ser inmigrante indocumentado hace que recree, en un bucle recursivo, su infructuosa búsqueda de vivienda, al chocar con múltiples reticencias por todos los frentes:

A mí me gustaría vivir en un piso como todo el mundo. Pero vas a algún sitio y te miran mal o te piden papeles, $y$ al no tener pues me dicen que no me la alquilan. Yo digo que voy a pagar, pero no se fían de mí y hace que tenga que estar aquí con mi gente. Al menos me siento acompañado (Dembele, comunicación personal, 5 de mayo de 2016).

Estas apreciaciones, similares a las que realiza Lumumba, o Joffre, senegalés del mismo campamento, no hacen sino visibilizar un proceso de construcción de la alteridad basado en la desigualdad, al asociarse el inmigrante con problemas, impagos o falta de mantenimiento de las viviendas (Olea, 2012). Muchos de los lugareños expresan en sus cotidianeidades que prefieren tener el piso cerrado a alquilarlo a un "moro o un negro", ya que no son responsables de su mantenimiento, lo cual no es sino una esencialización del inmigrante, asociándolo a categorías culturalmente negativas en la comunidad receptora, estigmatizando aún más su condición social.

Las formas que se tienen de negación a la vivienda son múltiples, tanto en sus formas como en su fondo. En ocasiones se recurre a solicitar alquileres abusivos, con cláusulas imposibles de poder asumir por parte del inmigrante (Olea, 2008; Rodríguez y Breva, 2012). En otras, la petición de documentación de trabajo o residencia, de la cual carecen o límites al número de ocupantes sencillamente hacen inviable cualquier intento de salir de los asentamientos, como se reflejan en las charlas cotidianas tanto con inmigrantes como con lugareños:

Yo quiero ir a un piso, pero cuando llego y me ven les cambia la cara. Son unos racistas. El otro día me pedían por un piso 700 euros mensuales y tenía que dar dos por adelantado y yo no tengo ese dinero. Encima me decían que solo podía vivir yo, que si metía a otro me echarían y me buscaría problemas (Lumumba, comunicación personal, 5 de marzo de 2016).

No contar con un espacio de vivienda digno, así como tener redes sociales limitadas, hace que el asentamiento temporal sea el único refugio para muchos de ellos, reproduciendo de esta manera los roles asignados a cada clase social, aceptando su confinamiento y hacinamiento en las afueras de las ciudades (Zizek, 2016), como un grupo excluido alejado de las zonas de confort urbana. Sin luz, ni agua, con ausencia de contenedores de recogida de residuos, al negarse las poblaciones a instalárselos amparándose en que viven en áreas 
periféricas externas a los espacios urbanos contemplados en los planes de ordenación urbanística, y como es de lógica sin redes de alcantarillado, los asentamientos deben autoorganizarse y defenderse ante agresiones externas, formando un locus étnico donde la solidaridad se confunde con la supervivencia del grupo.

Pasear por cualquier campamento nos remite a un espacio altamente precarizado. Con cocinas improvisadas dentro de las chabolas hechas con plásticos y cartón, "calles" y espacios abiertos donde desarrollan su cotidianeidad, la insalubridad campa por sus anchas así, como los fuegos. De esta forma, a lo largo de los últimos años no resulta infrecuente encontrar noticias referidas a incendios en los mismos lugares, perdiendo sus ocupantes el poco dinero que han podido reunir para enviar a sus familias, documentación importante de cara a su regularización e incluso, la vida

Aquí cocinamos dentro de la casa y también lo utilizamos para quitarnos el frío. Cogemos bidones de metal y hacemos ahí nuestras comidas. En invierno esto es muy frío y húmedo y nos duelen los huesos, tenemos que encender un fuego para poder calentarnos. A veces viene un viento y da fuego a la chabola y lo perdemos todo (Dembele, comunicación personal, 5 de mayo de 2016).

Pese a los constantes esfuerzos de las organizaciones humanitarias, lo cierto es que en no pocas ocasiones, muchos de los intentos de reubicación de los inmigrantes han caído en saco roto con la administración. De esta forma, el espacio se convierte en un generador de fronteras entre culturas, entre el que vive en el núcleo urbano y el que está en el bosque, el que se parece y el que se diferencia de la colectividad. Diferentes formas de generar asimetrías espaciales, de establecer los límites entre el sujeto y la otredad, en una clara mixofobia por todas las partes.

\section{La caridad no sustituye la solidaridad}

Una de las principales violencias que sufre el colectivo de inmigrantes asentados en los campamentos tiene un matiz eminentemente simbólico, y es que las relaciones asimétricas que se establecen con la sociedad hegemónica no son ni mucho menos favorables a ellos. En un claro brote etnocentrista, el inmigrante es visto como un ser desprotegido incapaz de tener capacidad de agencia, entrando en los circuitos de la dependencia y la caridad por parte de asociaciones, instituciones y vecindad. Ello hace que sus auto-ego-finalidades queden mermadas por la existencia de una limitación bienintencionada de sus capacidades, cayendo en los circuitos de la dependencia, como comenta Carlos, miembro de la ONG Proyecto Unidad de la Universidad de Huelva:

Me da pena lo que ocurre en los campamentos. Cuando llueve se hacinan en barrizales y en verano se asan de calor. No está bien dejarlos así de desprotegidos, hay que ayudarles para que tengan un mínimo de condiciones de vida. Desde la asociación, vamos periódicamente, de vez en cuando, a 
llevarles comida y medicamentos... (Carlos, comunicación personal, 8 de mayo de 2016).

Esta concepción claramente paternalista dentro de los límites del etnocentrismo, confiere al inmigrante una capacidad limitada de agencia, y le atribuye una incapacidad innata de alcanzar unos niveles mínimos de calidad de vida, constituyendo en sí una violencia simbólica de primer orden. También se considera que reproduce y legitima las asimetrías y desigualdades sociales así como, aunque resulte contradictorio, justifica la desigualdad, ya que con ello lo que hace es cronificar la problemática en cuestión.

Este paternalismo generará, en no pocas ocasiones, una confusión del rol que debe desempeñar cada actor en esta tragicomedia. A través de las observaciones realizadas en el lugar hemos podido comprobar cómo, de forma esporádica, vecinos de la localidad o proximidades llevan alimentos o ropas a los campamentos, en un intento bienintencionado de mitigar las deplorables condiciones de vida de sus inquilinos. Sin embargo, a la hora de entrar en el debate de si verían bien tener a unos de estos ocupantes como vecinos, la cosa cambia, amparándose en mil y una excusas:

Si ellos vienen como deben de venir por mí estupendo. Yo les traigo comida y la ropa que me dan mis vecinos, pero no me importaría que estuvieran de vecinos. Pero claro, siguiendo las normas de la comunidad donde vivo. No pueden meterse allí veinte en un piso ni pueden hacer lo que les de la gana porque hay unas normas que hay que cumplir y eso es de lógica (Alberto, comunicación personal, 27 de abril de 2016).

Esta cita no hace sino informarnos de la existencia de una profunda distancia entre los sujetos. A pesar de actuar desde la intersubjetividad, esta se encuentra llena de conflictos y prejuicios, estereotipando al inmigrante con cualidades negativas $y$, por tanto estigmatizándolo. Ello no hace sino hablar de imaginarios, lazos sociales y prácticas divergentes entre culturas, las cuales despiertan más recelo entre los sujetos, que otra cosa

No es que desconfíe de ellos, pero tienen costumbres que no tengo por qué tolerar. Al tercero [por su bloque de pisos] llegó un grupo de mauritanos y mataban las ovejas en la bañera, tenían unos olores muy fuertes entre sus hábitos higiénicos y sus ropas, así como por las noches se quedaban hablando hasta las tantas. Cuando se fueron el dueño del piso tuvo que dar dos manos de pintura al piso de cómo lo habían dejado (Manuel, comunicación personal, 30 de abril de 2016).

La alteridad es vista como conflicto en ambos casos. No se puede estigmatizar al inmigrante, como tampoco se puede demonizar al sujeto hegemónico. El choque de normas sociales, de imaginarios y la escasa capacidad de ambos en la gestión y resolución de conflictos, genera una lucha entre ambas concepciones de vida, al responder a modelos culturales muy diferenciados entre sí. 
Por esta razón la caridad, confundida con la solidaridad, se conforma como una poderosa herramienta de calma social, al apaciguar y justificar las contradicciones del sistema (Chouliaraki 2011). De un lado, el de la sociedad hegemónica, deriva la causa primigenia del problema hacia el inmigrante y su incapacidad de poder ser un sujeto con agencia propia, necesitando de la ayuda (etnocéntrica), al ser incapaces de poder alcanzar un nivel de progreso mínimo. Ello no hace sino justificar las relaciones de poder así como refuerza las clases presentes en este drama.

Por parte del inmigrante, esta relación de sumisión genera una pérdida de autoestima, una devaluación de su corporalidad, así como provoca una aceptación interesada de su rol de inferioridad. Accediendo a recursos de forma gratuita, por muy precarios que sean, hace que en muchas ocasiones entren en estados de desidia y falta de optimismo, aunque ello redunde en su cotidianeidad:

A mí me da igual ya todo. Vienen los de Cáritas o Cruz Roja a traernos alimentos, ropas y medicamentos, y con eso vamos tirando. Como no hay trabajo en el campo ¿qué voy a hacer yo? La verdad, al menos como y tengo techo, es más de lo que tenía en mi tierra (Lumumba, comunicación personal 5 de marzo de 2016).

La caridad así entendida no es sino una frontera simbólica intersubjetiva. Hace que el inmigrante viva en una liminalidad entre la legalidad y la ilegalidad, la dependencia y la independencia, entre el ser y el no-ser. Por muy sana que haya sido la acción, en realidad lo que se conseguirá será subsumir al inmigrante en una situación de mayor inferioridad al rol concedido por la sociedad en este macabro teatro.

Por esta razón, asociaciones como Cáritas o Cruz Roja han cambiado su estrategia de afrontamiento de la problemática, combinando su labor asistencial con la denuncia social y la puesta en marcha de campañas de sensibilización entre la ciudadanía, reclamando nuevas prácticas para con este colectivo (Peris, 2006; Cáritas, 2013), tales como programas de acceso a la vivienda, programas de inclusión o de generación de proyectos locales para la erradicación del chabolismo, muchos de ellos curiosamente similares a los puesto en marcha décadas atrás con la población gitana del entorno.

\section{CONCLUYENDO, QUE ES GERUNDIO}

El fenómeno de las migraciones, a pesar de tener efectos locales, debe ser evaluado a partir de las dinámicas globales y de las asimetrías sociales y económicas planetarias. Como diría Edgar Morin (1993), vivimos en una "tierra-patria", pero no es la misma casa para todos por igual. Los asentamientos de inmigrantes en la zona fresera onubense no son sino un reflejo más de las tensiones que se están produciendo en este mundo líquido, como diría Bauman (2005), siendo la actuación local tan solo una forma de enfrentamiento de la problemática a una escala reducida. 
Tan solo desde la necesidad de enfocar las relaciones con la alteridad desde un punto de vista solidario, que no caritativo, es como podremos llegar a alcanzar un nuevo orden mundial más justo e igualitario, como defienden autores como Zizek (2016), aunque sea a través de la crítica.

Como seres subjetivos que actúan desde la intersubjetividad, resulta imposible poder llegar a alcanzar una sociedad perfecta donde no existan conflictos, ya que el conflicto forma parte misma de la cultura y la socialidad humana (Haro, 2012). Sin embargo, desde el respeto de la diversidad cultural, con sus imaginarios, redes sociales y lazos igualmente diferentes por parte tanto del sujeto como desde la otredad, es como realmente se podrá empezar a vislumbrar el final de estas nuevas formas de esclavismo del siglo XXI.

\section{REFERENCIAS}

Appadurai, A. (2007). El rechazo de las minorías. Ensayo sobre la geografía de la furia. Barcelona: Tusquets.

Bauman, Z. (2005). Vidas desperdiciadas: La modernidad y sus parias. Madrid: Paidós.

Biasatti, S. y Compañy, G. (2014). Memorias sujetadas. Hacia una lectura crítica y situada de los procesos de memorialización. Madrid: Service Point.

Cáritas (2013). La situación de los temporeros agrícolas acompañados por Cáritas. Madrid: Cáritas.

Comisiones Obreras (2016). Dossier asentamientos en Huelva. Huelva: Servicio de Publicaciones de CCOO.

Chouliaraki, L. (2011). 'Improper distance': Towards a critical account of solidarity as irony. International Journal of Cultural Studies, 14(4), 363-381.

Dagnino, E., Olvera, A. y Panfichi, A. (2006). La disputa por la construcción democrática en América Latina. México: Fondo de Cultura Económica.

Delgado, M. (2011). ¿Quién puede ser inmigrante en la ciudad? Mugak, (18). Recuperado de http://mugak.eu/revista-mugak/no-18/quien-puede-ser-inmigrante-en-la-ciudad

Delgado, M. (2006). Círculos virtuosos. Nuevos lenguajes para la exclusión social. En R. Bergalli (Ed.) Flujos migratorios y su (des)control. Puntos de vista interdisciplinares (pp. 1-24). Barcelona: Anthropos.

Foro para la Integración Social de Inmigrantes (2007). Informe sobre la Situación de la Integración Social de los Inmigrantes y Refugiados. Madrid: Ministerio de Trabajo y Asuntos Sociales.

Foucault, M.(2000). Vigilar y castigar. Buenos Aires: Siglo XXI.

Girard, R. (2005). La violencia y lo sagrado. Barcelona: Anagrama.

Haro, A. (2014). La globalización y sus parias. A propósito de Zygmunt Bauman. Ehquidad International Welfare Policies an Social Work journal, (2), 25-64. 
Haro, A. (2012). Antropología del conflicto. Reflexiones sobre el nuevo orden global. Convergencia, Revista de Ciencias Sociales, (60), 177-204.

Instituto Nacional de Estadística (INE) (2017). Padrones municipales de habitantes del Instituto Nacional de Estadística. Municipio de Palos de la Frontera Recuperado de http://www.ine.es/jaxi/Tabla.htm?path=/t20/e245/ p04/provi/10/\&file=0ccaa002.px

Llobera, J. (1990). La identidad de la Antropología. Barcelona: Anagrama.

Marcus, G. (2001). Etnografía en/del sistema mundo. El surgimiento de la etnografía multilocal. Alteridades, 11(22), 111-127

Miedes, B. y Redondo, D. (2007). Trabajadoras extranjeras en los campos freseros, de la necesidad a la invisibilidad. Trabajo: Revista andaluza de relaciones laborales, (20), 183-205.

Morin, E. (2004). Introducción al pensamiento complejo. México: Editorial Gedisa.

Morin, E. (1993) Tierra Patria. Buenos Aires: Nueva Visión.

Olea, S. (2012). Vivienda, ¿derecho o regalo? Exclusión y Desarrollo social. Análisis y perspectivas (pp. 39-46). Madrid: Cáritas Española/Fundación Foessa.

Olea, S. (2008). Documento base campaña Sin Techo 2008. "No tener hogar significa mucho más que estar sin techo”. Madrid: Cáritas Editorial.

Peris, J. (2006). Acercamiento a la realidad migratoria de Huelva desde el trabajo de campo del programa de exclusión de Cáritas Diocesana-Huelva. Alternativas: Cuadernos de Trabajo Social, (14), 14-26.

Pogge, T. (2000). On the site of Distributive Justice. Philosophy Public Affairs, 29(2), 137 169.

Pozzoli, M. T. (2006). El sujeto de la complejidad. La construcción de un Modelo Teórico Transdisciplinar (eco-psico-socio-histórico-educativo). Polis, Revista de la Universidad Bolivariana, 5(15), 1-16.

Rodríguez, J. y Breva, J.M. (2012). Asentamientos e inmigración. El caso de Huelva. En AAVV (Eds.) Acompañándo...nos. Mirada, acción y propuestas de Cáritas con personas que están sin hogar (pp. 415-424). Madrid: Cáritas.

Solana, J. L. (2002). La dimensión cultural en el trabajo social con población inmigrante (una perspectiva desde la Antropología Social). Portularia, (2), 139-155.

Solana, J. L. (2000). Antropología y complejidad humana. La antropología compleja de Edgar Morin. Jaén: Comares Editorial.

Zizek, S. (2016). La nueva lucha de clases. Barcelona: Anagrama. 